\title{
Desenvolvimento de aplicativos na/para a educação pública: uma parceria entre estudantes do ensino médio e graduandos Elmara Pereira de Souza ${ }^{1}$, Adriana Santos Sousa ${ }^{1}$, Luisa Souza Moura ${ }^{2}$ \\ ${ }^{1}$ Centro Juvenil de Ciência e Cultura de Vitória da Conquista - BA (CJCC) - Vitória da Conquista - BA - Brasil \\ ${ }^{2}$ Universidade de São Paulo - Campus São Carlos \\ elmara.souzalenova.educacao.ba.gov.br, \\ adriana.sousalenova.educacao.ba.gov.br, luisasouzamoura@gmail.com
}

\begin{abstract}
This paper presents the experience of developing applications for public education by high school students of the Centro Juvenil de Ciência e Cultura de Vitória da Conquista-BA in partnership with undergraduates. The main objective of the project is to provide the authorship of the students as a strategy for the construction of knowledge. The TripQuest and CartoGráfico applications are interdisciplinary and can favor learning in a ludic way. This experience shows that it is possible to create authoring spaces so that young people from public schools are not mere reproducers and users of what is already done, but producers, authors of educational content.
\end{abstract}

Resumo. Este artigo apresenta a experiência do desenvolvimento de aplicativos para a educação pública por alunos do ensino médio do Centro Juvenil de Ciência e Cultura de Vitória da Conquista-BA em parceria com graduandos. O principal objetivo do projeto é proporcionar a autoria dos estudantes como estratégia para a construção do conhecimento. Os aplicativos TripQuest e CartoGráfico são interdisciplinares e podem favorecer a aprendizagem de forma lúdica. Esta experiência demonstra que é possivel criar espaços de autoria para que os jovens das escolas públicas não sejam meros reprodutores e usuários do que já está produzido, mas produtores, autores de conteúdos educacionais.

\section{Introdução}

As discussões sobre a utilização das tecnologias digitais na educação vêm de longas datas. No final dos anos 1980 começam a chegar às escolas os laboratórios de informática. No anos 1990 com a utilização de software educativos o computador como recurso pedagógico dá os seus primeiros passos. Nos anos 2000, surgiram os software educativos por distribuição web. A web2.0, com sua gama de serviços, proporcionou um espaço para aplicações educacionais na perspectiva cliente-servidor, assim como, o surgimento de Objetos de Aprendizagem (OA), Recursos Educacionais Abertos (REA), Software Educacionais Livres e, mais recentemente, Aplicativos móveis (APP).

Atualmente, vivemos uma era em que as tecnologias digitais avançam a passos largos. Porém, a sua utilização na educação na perspectiva da criação, da autoria ainda precisa avançar. Segundo Souza (2013) essas tecnologias podem nos conduzir à produção do diferente, à invenção, ao exercício da alteridade e, talvez, numa afetação 
VIII Congresso Brasileiro de Informática na Educação (CBIE 2019)

Anais do XXV Workshop de Informática na Escola (WIE 2019)

mútua, possam ajudar a produzir novas educações, novas possibilidades de produção de saberes, novos devires.

É nesta perspectiva do uso das tecnologias digitais como propulsora da autoria, do protagonismo dos jovens, da invenção de novas formas de ensinar e aprender, da busca por caminhos que possibilitem inovar na educação que se apresenta este trabalho.

Trataremos, neste artigo, especificamente do relato da experiência da produção de dois aplicativos: TripQuest e Cartográfico, desenvolvidos de maio a dezembro de 2018 por alunos do CJCC em parceria com estudantes da Universidade Estadual do Sudoeste da Bahia - UESB), Instituto Federal da Bahia - IFBA e Universidade de São Paulo - USP. Estes aplicativos foram finalistas da Maratona "Tecnologias móveis na escola", organizada pela Associação para Promoção da Excelência do Software Brasileiro - SOFTEX em parceria com o Fundo das Nações Unidas para a Infância UNICEF e SAMSUNG (2018).

\section{Contextualização}

Para que o desenvolvimento de aplicativos possa ser implementado na educação básica é necessário um ambiente favorável, uma escola aberta à temas contemporâneos e que promova o desenvolvimento de competências baseadas na Base Nacional Comum Curricular - BNCC (2017). A parceria entre jovens do ensino médio com graduandos pode proporcionar, além do desenvolvimento do pensamento computacional e outras possibilidades de construção do conhecimento, o desenvolvimento de competências importantes como: Atuar em grupo e demonstrar interesse em construir novas relações, respeitando a diversidade e solidarizando-se com os outros; Aprender a tomar decisões levando em consideração as necessidades do grupo, resolvendo os possíveis entraves e conflitos; Compreender o sentido de alteridade, ou seja, se colocar no lugar do outro, relacionar-se com o outro; Estimular o pensamento crítico, a autonomia e a formação para a cidadania.

Compreendendo a importância do desenvolvimento destas competência e o potencial do desenvolvimento de aplicativos no processo educacional, o Centro Juvenil de Ciência e Cultura - CJCC de Vitória da Conquista criou a Incubadora de Projetos para que os alunos possam produzir os seus próprios projetos com orientação dos professores e parceria com estudantes de Instituições de Ensino Superior.

O principal objetivo desses projetos é o favorecimento à autoria dos estudantes. $\mathrm{O}$ conceito de autoria, nesse trabalho, tem base nos pressupostos teóricos de Mikhail Bakhtin [2000] e é compreendido como toda e qualquer construção feita pelo sujeito, pela qual se responsabilize, seja através da linguagem oral ou escrita, ou da ação, perpassada pelo social, considerando a influência do outro como essencial no processo de criação [Souza 2016].

\subsection{Centro Juvenil de Ciência e Cultura}

O CJCC é uma escola pública vinculada à Secretaria de Educação do Estado da Bahia e visa o fortalecimento da educação complementar e a diversificação do currículo nas escolas públicas estaduais. 
VIII Congresso Brasileiro de Informática na Educação (CBIE 2019)

Anais do XXV Workshop de Informática na Escola (WIE 2019)

O CJCC oferece ao estudante, nos turnos opostos ao período de aula regular, uma diversidade de atividades culturais, cursos, oficinas e de acesso ao conhecimento científico. A proposta é provocar a curiosidade dos estudantes e incentivá-los a criar "uma nova relação com o ato de aprender, motivada pelo prazer genuíno da descoberta" [CJCC 2015, p. 3]. Nenhuma atividade é obrigatória e a participação ocorre por adesão.

Em 2017, foi criada no CJCC de Vitória da Conquista a Incubadora de Projetos com o objetivo de ser um espaço de autoria para que esses alunos pudessem desenvolver projetos de pesquisa e produtos a partir de suas próprias ideias. Diferente dos cursos, na incubadora não há tempo determinado ou carga horária definida. As reuniões acontecem uma vez por semana (todas as quartas-feiras das $14 \mathrm{~h}$ às $18 \mathrm{~h}$ ) no laboratório de informática da Universidade Aberta do Brasil - UAB. Foi necessário fazer parceria com o polo UAB, pois, naquela época, o Centro Juvenil não possuía computadores para o desenvolvimento dos aplicativos.

Em 2018, a partir de várias discussões sobre questões sociais, foram identificados problemas relacionados à educação e os estudantes decidiram criar aplicativos que favorecessem a aprendizagem de estudantes de escolas públicas. As temáticas dos aplicativos foram definidas com base em pesquisas, análises dos índices da educação no Brasil e da propria experiência do grupo. Assim, foram desenvolvidos os aplicativos TripQuest e CartoGráfico, contextualizados a seguir.

\subsection{TripQuest}

No contexto contemporâneo em que as culturas estão em constante interconexão, aprender inglês é muito importante. Porém, apenas 5\% dos brasileiros falam inglês e somente 3\% são fluentes na língua (Education First, 2018). O estudo da EF (2018) mostra que, entre 88 países, o Brasil ocupa a $53^{\mathrm{a}}$ posição em proficiência em inglês.

O ensino de inglês nas escolas públicas brasileiras não tem sido eficiente, há poucas iniciativas para transformar o ensino de inglês em algo prazeroso e para fazer com que os alunos da educação básica da rede pública consigam se comunicar neste idioma. A pesquisa "O ensino do inglês na educação pública brasileira", realizada pelo British Council (2015) indica alguns problemas: formação de professores, poucas aulas semanais, enfoque em questões gramaticais e não na efetiva comunicação, metodologias desvinculadas do interesse dos alunos, entre outros. Se analisarmos o cotidiano das nossas salas de aula, é possível verificar que os métodos utilizados para ensinar inglês são muito prescritivos. Há uma maior preocupação com a decodificação, a repetição e a memorização de estruturas gramaticais de modo abstrato, descontextualizadas de situações enunciativas concretas, muitas vezes alheias à realidade linguística dos estudantes [Oliveira, 2015; Leffa, 2016, apud Silva et al, 2017].

Analisando a Base Nacional Comum Curricular - BNCC de Língua Inglesa verificamos a importância de aprender inglês a partir da reflexão da presença dessa língua estrangeira no cotidiano, incentivando as práticas discursivas e linguísticas.

Pensando nesse problema, compreendendo a importância da interdisciplinaridade e a necessidade da criação de recursos educacionais que apoiem professores e alunos no processo de ensino-aprendizagem é que se insere o TripQuest. $\mathrm{O}$ aplicativo é inspirado na lógica de um Role-playing Game - RPG, jogo de 
VIII Congresso Brasileiro de Informática na Educação (CBIE 2019)

Anais do XXV Workshop de Informática na Escola (WIE 2019)

interpretação de personagens/papéis, e tem o objetivo de favorecer a aprendizagem da língua inglesa e história através de enunciados concretos e narrativas envolventes. $\mathrm{O}$ jogo foi desenvolvido com base em conteúdos do $9^{\circ}$ ano do ensino fundamental, em especial, verbos modais (can, could, should, must, have to, may e might); WH questions words; comparativos e superlativos, além de abordar o conteúdo de História relacionado a primeira e segunda guerras mundiais.

\subsection{CartoGráfico}

A ideia do CartoGráfico surgiu pela diversidade regional da formação da equipe (Bahia e São Paulo) que ficaram explícitas durante as primeiras reuniões: costumes diferentes, sotaques marcantes, vocabulários característicos entre outros. Surgiu a necessidade de conhecer um pouco mais sobre o outro, seus costumes, culturas, peculiaridades que caracterizam "seu lugar". Como o objetivo era criar aplicativos interdisciplinares, o grupo decidiu unir a geografia e a matemática.

O CartoGráfico é um jogo educativo para dispositivos móveis que pode ser utilizado por alunos de qualquer série doa nos finais do Ensino Fundamental e do Ensino Médio, embora aborde conteúdos de Geografia (características físicas e humanas sobre cidades/regiões brasileiras) e Matemática (coordenadas cartesianas, lateralidade, estratégia e raciocínio lógico) desenvolvidos especialmente no $7^{\circ}$ ano do Ensino Fundamental II.

\section{Métodos}

Iniciamos os projetos buscando parcerias com graduandos de Universidades públicas. Os alunos do CJCC que fazem parte da Incubadora de Projetos participam de cursos como: ProgramAÍ - Introdução à lógica de programação; Criando Games - criação de jogos no Scratch; e Inventores de App - produção de aplicativos no App Inventor. Porém, apesar de participarem de um ou mais cursos na área das tecnologias, os alunos não são programadores. Por isso, foi fundamental a parceria com alunos do ensino superior. As equipes foram montadas da seguinte forma: TripQuest - um aluno e um professor do Centro Juvenil e dois alunos de graduação em Ciência da Computação da Universidade Estadual do Sudoeste da Bahia - UESB, um estudante de Sistemas de Informação do Instituto Federal da Bahia - IFBA; CartoGráfico, um aluno, uma professora do Centro Juvenil e três estudantes de Ciência da Computação da Universidade de São Paulo - USP, campus São Carlos. Estas parcerias extrapolaram as barreiras regionais, proporcionando a conexão de estudantes da Bahia com estudantes de São Paulo.

\subsection{TripQuest}

O Trip Quest é um aplicativo para dispositivos móveis inspirado na lógica de um RPG, jogo colaborativo em que as pessoas participam de narrativas guiadas por um "mestre" que narra a história para os jogadores que, por sua vez, tomam decisões em grupo para resolver os desafios propostos. O Trip Quest simula situações de uma viagem que desafiam os alunos a se comunicarem em inglês, compreenderem palavras, frases e expressões nesse idioma, assim como, estudarem fatos históricos. Na tela inicial há os botões: (1) Iniciar - dá início ao jogo; (2) Como Jogar - tutorial explicando as regras do jogo; (3) Guia do professor - indica as competências e sugere estartégias pedagógicas 
VIII Congresso Brasileiro de Informática na Educação (CBIE 2019)

Anais do XXV Workshop de Informática na Escola (WIE 2019)

para o $9^{\circ}$ ano do ensino fundamental; (4) Créditos - informações sobre os autores. No jogo, os estudantes são convidados a se integrarem à narrativa de uma viagem; ao continuar é apresentada a primeira Quest e os grupos têm um determinado tempo e dinheiro para executar os desafios; segue para os desafios (figura 1). A proposta do Trip Quest é que seja jogado por toda a turma ao mesmo tempo e que o professor seja o coordenador/mestre.

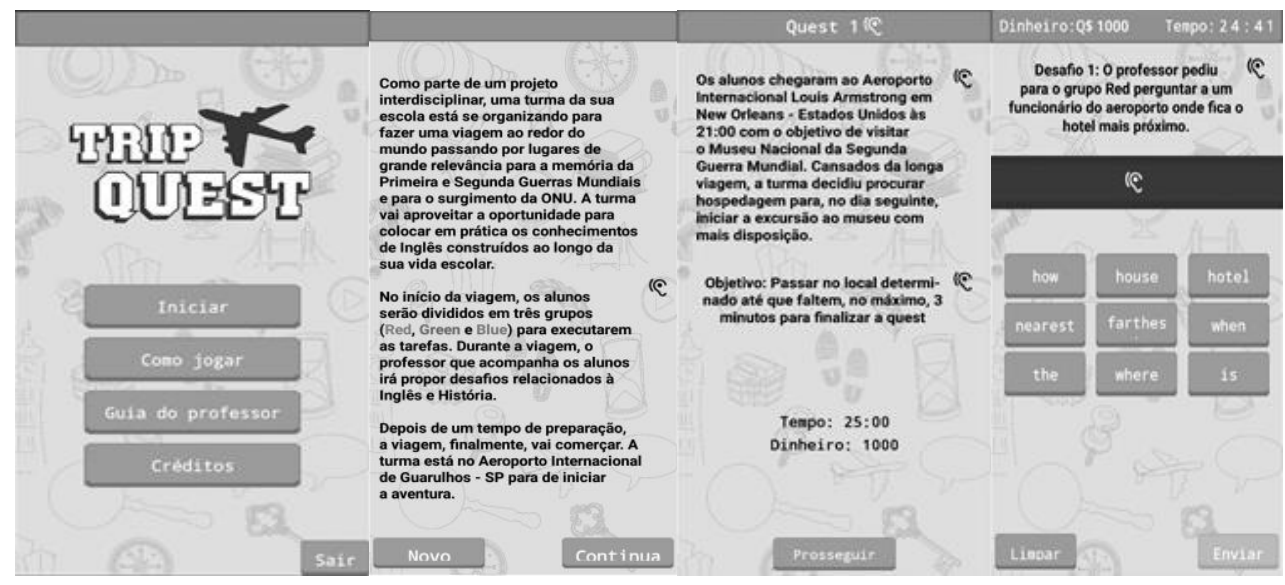

Figura 1: Telas do TripQuest

Os principais objetivos do Trip Quest são: (1) Possibilitar aos alunos a comunicação em inglês de forma lúdica, ou seja, aprender brincando e com prazer; [Santos, 2000]; (2) Conhecer uma parte da história de países de língua inglesa, (2) Tornar mais interessante e divertido o estudo de inglês e história (3) Desenvolver habilidade de trabalhar coletiva e colaborativamente e tomar decisões em grupo.

O jogo foi desenvolvido no App Inventor, uma aplicação mantida pelo Massachusetts Institute of Technology - MIT que possibilita a produção de aplicativos através da programação em blocos, sem a necessidade de um conhecimento prévio de uma linguagem de programação textual.

Antes do processo de desenvolvimento na plataforma de programação em blocos, a equipe se reuniu para realizar o planejamento técnico e foi montado um fluxograma com as ações que ocorreriam dentro do aplicativo. Esse fluxograma possibilitou agilidade na implementação do projeto, uma vez que o seu objetivo foi de definir quais seriam as transições de telas, as entradas dos dados, entre outros.

O planejamento envolveu a criação de um modelo de banco de dados para facilitar a compreensão de como os dados seriam armazenados e de que modo poderiam ser consultados. Assim, foi possível agilizar o processo de desenvolvimento já que os modelos e fluxograma construídos continham boa parte da estrutura de programação necessária. Para armazenamento dos dados foi utilizada uma extensão para o App Inventor, o SQLite, que possibilitou o gerenciamento das informações utilizadas no aplicativo. O Trip Quest está disponível na Play Store.

\subsection{CartoGráfico}

O CartoGráfico foi desenvolvido online, pois parte da equipe estava na Bahia e outra parte em São Carlos - SP. Para a construção do aplicativo foi criado e compartilhado um 
VIII Congresso Brasileiro de Informática na Educação (CBIE 2019)

Anais do XXV Workshop de Informática na Escola (WIE 2019)

Game Design Document - GDD em que constava as diretrizes iniciais do aplicativo como: conceito do jogo, ambientação, descrição das fases e ciclos das partidas. O GDD serviu como guia do nosso trabalho. As tarefas foram divididas entre os membros do grupo e a cada semana havia uma reunião online por meio do WhatsApp e Hangouts para atualizar as informações, discutir e definir os caminhos teóricos, pedagógicos a seguir.

Foi utilizada a plataforma Unity para o desenvolvimento do aplicativo. Na tela inicial o usuário pode escolher: (1)Jogar - iniciar o jogo, (2)Tutorial - verificar as instruções do jogo; (3)Para professores - ler as estratégias pedagógicas sugeridas para o uso do jogo na sala de aula; (4)Créditos - informação sobre os autores. Em seguida tem início o jogo.

O aplicativo permite que o usuário viaje pelo Brasil conhecendo as regiões e suas características (clima, cultura, culinária, relevo, pontos turísticos, singularidades de cada região) visitando pontos turísticos das capitais dos estados (figura 2).

A cada cidade visitada, o estudante localiza-se no mapa, utilizando estratégias e raciocínio lógico para escolher o melhor e menor trajeto para chegar ao ponto turístico desejado respondendo corretamente às perguntas apresentadas. $\mathrm{O}$ personagem avança a cada resposta correta e, quando erra, o personagem permanece no mesmo lugar. Independente de acertar ou errar, o usuário recebe um feedback com um texto complementar referente ao assunto da questão.

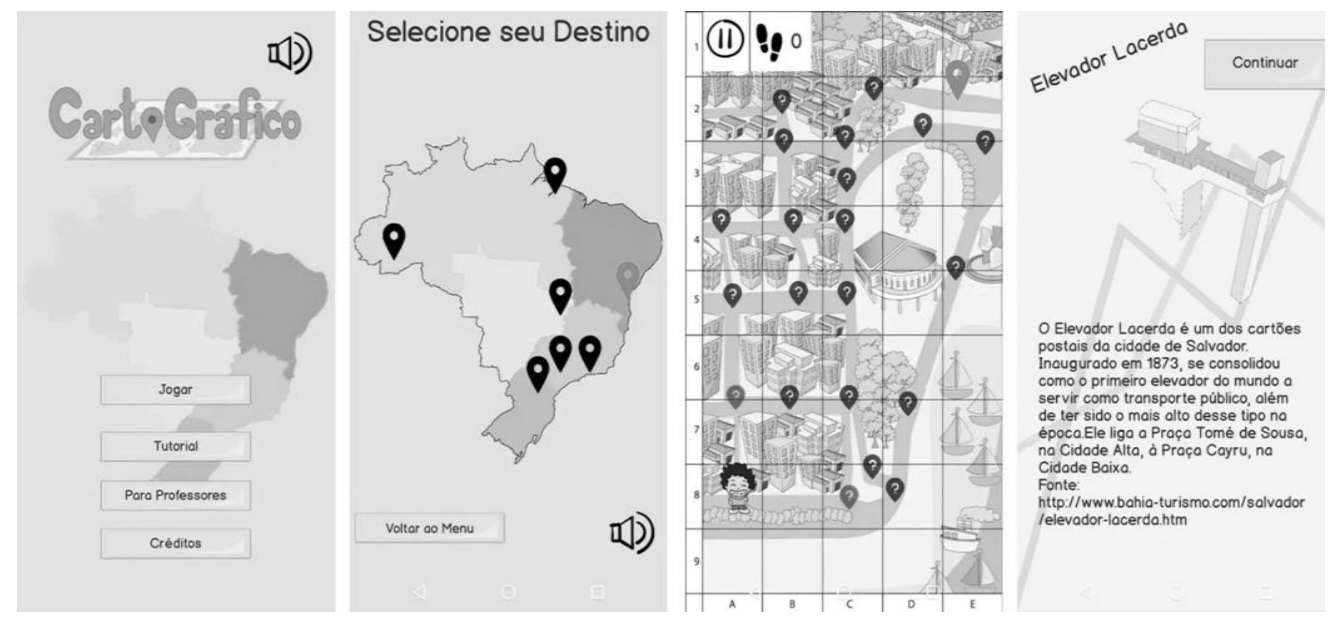

Figura 2: Telas do CartoGráfico

Ao chegar ao destino, o personagem obtém informações sobre o ponto turístico e a pontuação que varia de uma a cinco estrelas, de acordo com a estratégia utilizada na elaboração do trajeto para o ponto turístico (quanto menos passos, mais estrelas são obtidas). Nesta tela também existe a possibilidade de compartilhamento do aplicativo por meio de WhatsApp e Twitter.

\section{Resultados e Discussões}

Os aplicativos foram testados em uma escola pública estadual de ensino fundamental de Vitória da Conquista. 
VIII Congresso Brasileiro de Informática na Educação (CBIE 2019)

Anais do XXV Workshop de Informática na Escola (WIE 2019)

O teste do protótipo do Trip Quest foi feito com 28 alunos do $9^{\circ}$ ano do ensino fundamental (figura 3). Inicialmente, a professora de inglês dividiu a turma em três grupos (red, green e blue), conforme sugerido no guia do professor que faz parte do aplicativo.

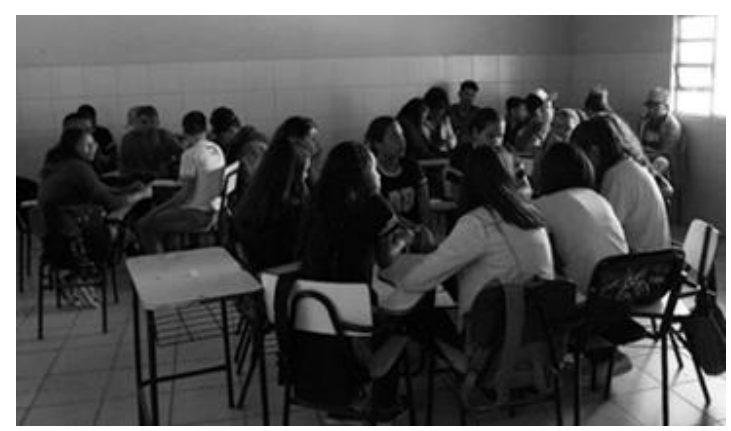

Figura 3: Testagem do aplicativo TripQuest

A proposta inicial era que apenas a professora tivesse o celular e conduzisse o jogo. O Trip Quest deveria ser projetado por um datashow para que todos pudessem acompanhar a narrativa e os desafios. Porém, em função da dificuldade em acessar a internet na escola, não foi possível refletir a imagem do celular no notebook para fazer a projeção. Então, a solução foi deixar um celular com cada grupo para que pudesse acompanhar a narrativa, utilizar e avaliar o aplicativo. Essa ação foi positiva na medida em que os alunos puderam acompanhar o jogo no próprio celular, verificar o vocabulário de cada desafio e se sentir, de fato, utilizando o aplicativo. Porém, identificamos um ponto negativo quando um dos grupos avançou o jogo no seu celular e não acompanhou a narrativa da professora, dificultando a colaboração entre os grupos, princípio do Trip Quest.

Após a etapa de distribuição dos celulares para os grupos, a professora iniciou a narrativa. Observamos que quando o desafio era para um grupo (red, por exemplo), os outros dois grupos (blue e green) ficavam inquietos. Naquele momento, consideramos mais interessante que os três grupos tentassem responder todas as questões, mas a professora deveria inserir no aplicativo a resposta dada pelo grupo determinado para aquele desafio. Assim, a dispersão diminuiu, pois todos ficaram envolvidos tentando resolver os desafios. Após a resolução e, consequentemente, a chegada ao final da quest (conjunto de desafios), a professora de História narrou o texto apresentado no aplicativo sobre a segunda guerra mundial e leu o quiz. A turma acertou as três perguntas propostas e conseguiu chegar ao final do jogo com sucesso, porém, em um tempo maior do que o proposto na quest.

Analisando os questionários de avaliação, identificamos que as duas professoras avaliaram o Trip Quest como coerente com as competências e habilidades dos componentes curriculares (inglês e história), adequado ao $9^{\circ}$ ano, atrativo e inovador, podendo ajudar a melhorar a aprendizagem dos alunos. Elas consideraram fácil a navegação e disseram que o app pode contribuir para a melhoria da aprendizagem do estudante.

Quanto à análise das avaliações dos estudantes, verificamos que 96\% consideraram que o Trip Quest aborda conteúdos de inglês e história; $86 \%$ indicaram que o app é adequado para o ano escolar em que estudam; 64\% consideraram a proposta 
VIII Congresso Brasileiro de Informática na Educação (CBIE 2019)

Anais do XXV Workshop de Informática na Escola (WIE 2019)

do aplicativo inovadora e atrativa, assim como, que ele pode ajudar a melhorar a aprendizagem (figura 4). Considerando que os jovens se interessam pelas tecnologias digitais, em especial, por jogos, $75 \%$ responderam que gostariam que o professor utilizasse aplicativos na sala de aula. A maioria (86\%) disse que foi fácil navegar no Trip Quest.

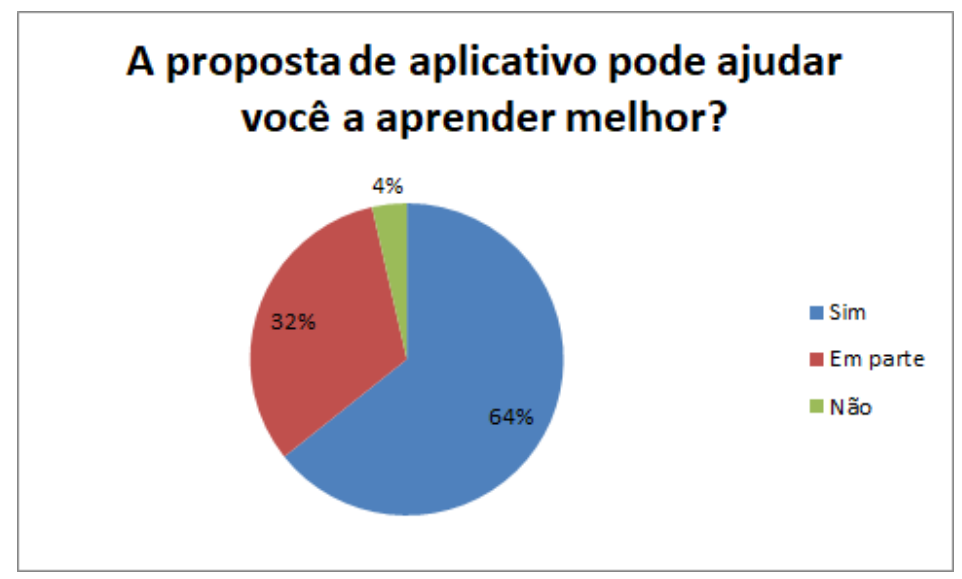

Figura 4: Gráfico relacionado às respostas dos alunos

Os alunos fizeram sugestões para melhorar o aplicativo, das quais três foram consideradas viáveis para serem implementadas. São elas: fazer mais perguntas/desafios na quest que está disponível, desenvolver outras quests e inserir áudio para que o aplicativo fique mais acessível. Esta última sugestão foi implementada logo após a testagem e está disponível na versão que está na Play Store.

Já o CartoGráfico foi testado com 71 alunos, uma professora de Matemática e outra de Geografia do $7^{\circ}$ Ano do ensino fundamental. Os alunos e professoras responderam os questionários de coleta de dados. As professoras afirmaram que se sentiram motivadas para usar o aplicativo. Mesmo com dificuldades de acesso à internet na escola conseguiram incorporar o recurso ao planejamento das aulas. Os alunos fizeram o download do app além de utilizar atividades complementares como: elaboração de blog, elaboração de mapas e maquetes com tamanhos proporcionais ao reais. Neste caso, a inserção dos recursos digitais em atividades pedagógicas exige dos professores outras estratégias para a construção do conhecimento e para a aprendizagem, exercendo a função de intermediador entre conteúdo, estudante e tecnologia.

Cerca de $85 \%$ dos estudantes concordam que gostariam que o professor inserisse o aplicativo em sala de aula e nenhum deles fez restrição ao uso desta tecnologia nas aulas (figura 5). 
VIII Congresso Brasileiro de Informática na Educação (CBIE 2019)

Anais do XXV Workshop de Informática na Escola (WIE 2019)

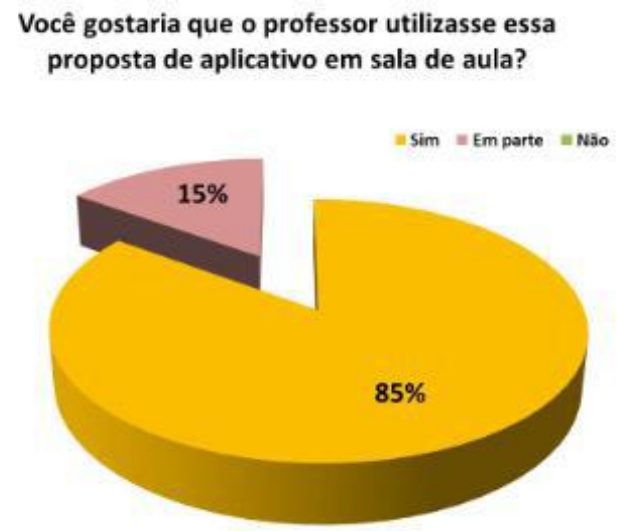

Figura 5: Gráfico relacionado às respostas dos alunos

Dos estudantes que participaram da pesquisa, $87 \%$ afirmaram que aprenderam melhor o conteúdo abordado por meio do uso do aplicativo. Esse dado reforça a afirmação de Prensky (2010, pág. 28) quando diz que "as crianças de hoje querem ser envolvidas e os games não só as envolvem, mas também ensinam lições valiosas durante o processo". É uma oportunidade que os jovens têm de obter um aprendizado prazeroso, não enfadonho.

O Trip Quest e o CartoGráfico foram dois dos 32 projetos brasileiros premiados na Maratona Tecnologias Móveis na Escola promovida pela Unicef e Samsung (UNICEF, 2018) e apoiada pelo Ministério da Educação. Com apoio da Secretaria de Educação do Estado da Bahia, os alunos que produziram o aplicativo apresentaram o protótipo para avaliadores na Universidade de São Paulo, tiveram a oportunidade de conhecer os outros finalistas e visitar grandes empresas de tecnologia. Os membros da equipe receberam premiação em dinheiro e equipamentos. Foi uma experiência enriquecedora e marcante para os estudantes e professoras da educação pública. A parceria criada neste projeto, aproximou estudantes de ensino médio da universidade, despertando o desejo dos alunos da educação básica da escola pública de se aprofundarem nos estudos e vislumbrar um curso superior como possibilidade de futuro.

\section{Conclusões}

A experiência do desenvolvimento de aplicativos por alunos do Centro Juvenil de Ciência e Cultura de Vitória da Conquista demonstra que é possível criar espaços de autoria para que os jovens das escolas públicas não sejam meros reprodutores e usuários do que já está produzido, mas produtores, autores de conteúdos educacionais.

Considerando as inúmeras dificuldades no ensino e aprendizagem nas escolas públicas do Brasil, concluímos que os aplicativos Trip Quest e CartoGráfico: (1) se aproximam do interesse dos jovens, pois eles se interessam por jogos e aplicativos; (2) favorecem a aprendizagem de forma lúdica; (3) levam para a sala de aula ferramentas que tornam a aprendizagem mais leve e divertida, tornando-a mais atrativa e natural.

Os aplicativos também buscam desenvolver competências, descritas na BNCC, importantes não só para a educação, mas para a vida, como: (1) atuar em grupo e demonstrar interesse em construir novas relações, respeitando a diversidade $\mathrm{e}$ solidarizando-se com os outros; (2) aprender a tomar decisões levando em consideração 
VIII Congresso Brasileiro de Informática na Educação (CBIE 2019)

Anais do XXV Workshop de Informática na Escola (WIE 2019)

as necessidades do grupo, resolvendo os possíveis entraves e conflitos; (3) compreender o sentido de alteridade, ou seja, se colocar no lugar do outro, relacionar-se com o outro; (5) estimular o pensamento crítico, a autonomia e a formação para a cidadania.

Os protótipos dos aplicativos estão disponíveis na Play Store para que qualquer pessoa possa fazer o download gratuitamente. Como trabalhos futuros pretendemos no TripQuest desenvolver novas quests para diferentes níveis de inglês, favorecendo o uso do aplicativo em outras séries do ensino fundamental e médio e no CartoGráfico criar desafios relacionadas à outras cidades brasileiras.

\section{Referências}

Bakhtin, M. (2000). Estética da Criação Verbal. São Paulo, Martinz Fontes.

Brasil (2017). Ministério da Educação. Base Nacional Comum Curricular. Brasília: MEC.

British Council. (2015) O ensino do Inglês na Educação Pública Brasileira. São Paulo, SP.. Disponível

em https://www.britishcouncil.org.br/sites/default/files/estudo_oensinodoinglesnaeducac aopublicabrasileira.pdf Acessado em 01/06/2018

CJCC 2015. Centro Juvenil de Ciência e Cultura - Documento - Base. Disponível em http://institucional.educacao.ba.gov.br/centrosjuvenis [Acessado em 02/07/2019].

EF Education First (2018).. O Índice de Proficiência em Inglês da EF. Disponível em https://www.ef.com.br/_/ /media/centralefcom/epi/downloads/full-reports/v8/efepi-2018-portuguese.pdf Acessado em 01/02/2019.

Silva, W et al. Revista A cor das Letras (2017).. Revista Digital dos Programas de PósGraduação do Departamento de Letras e Artes da UEFS Feira de Santana, v. 18, n. Especial, p. 163-181, outubro-dezembro/2017 Disponível em http://periodicos.uefs.br/index.php/acordasletras/article/view/2706 Acessado em $15 / 08 / 2018$.

Prensky, M. "Não me atrapalhe, mãe - Eu estou aprendendo!" Como os vídeogames estão preparando nossos filhos para o sucesso no século XXI - e como você pode ajudar!; tradução Lívia Bergo - São Paulo: Phorte Editora, 2010.

Santos, S. M. P. A ludicidade como ciência. Petrópolis: Vozes, 2001.

Souza, E. P. (2016). Construção de sentido e autoria na formação de professores para a utilização das tecnologias digitais na educação. In: AXT, Margarete; AMADOR, Fernanda; REMIÃO, Joelma. Experimentações Ético-Estéticas em pesquisa na educação. Panorama Cultural. Porto Alegre.

Souza, E. P.(2013). Cartografia da produção de subjetividade em ambiente virtual de aprendizagem para a formação de docentes online. Tese de doutorado. Faculdade de Educação. Universidade Federal da Bahia, 2013. Disponível em http://repositorio.ufba.br/ri/handle/ri/18167

UNICEF. 2018. Fundo das Nações Unidas para a Infância. http://maratona.brasilmaisti.com.br/docs/Apresentacao_dos_projetos_V4.pdf Acessado em 01/03/2019. 